\title{
EFEK BUDAYA MERANTAU DAN MATRILINEAL SUKU MINANKABAU DALAM KOMUNIKASI DALAM KELUARGA DI DAERAH PERANTAUAN
}

\author{
Muhammad Ihsan Zaky \\ Email: zakyihsan260@gmail.com \\ Program Studi IlmuKomunikasi, Universitas Negeri Jakarta, \\ Jl. RawamangunMuka RT.11/RW.14, Rawamangun, PuloGadung, Kota \\ Jakarta Timur, DKI Jakarta, 13220, Indonesia. \\ Submitted: 29 Juni 2020| Accepted: 24 September 2020 | Published: 30 Desember \\ 2020 \\ Website: https://e-journal.umc.ac.id/index.php/jike/index
}

\begin{abstract}
With the modern era, culture is now often left behind, with the excuse that it has been left behind. Especially in the souls of young people who tend to follow the trend. Building a feeling of cultural love can be done by showing an identity and privilege. There are many cultures and customs that exist in Indonesia, one of which is the custom of Kabau. There are two cultures that are very prominent in the Minang custom, namely wandering and matrilineal culture. These two cultures really affect Minang children, especially in the family and overseas. The formulation of the problem is how does culture affect the character of children? The purpose of this study is to determine the influence of culture in educating children in the family sphere. The research method used is a qualitative method. In this study, I used a descriptive qualitative research method. This method is applied by describing the results of my interview with the Minangkabau tribe couple who migrate and live overseas.
\end{abstract}

Keywords: Komunikasi lintas budaya, Adat Minangkabau, Matrilineal,Rantau

\begin{abstract}
Abstrak
Dengan adanya zaman serba modern, kini budaya sering kali di tinggalkan, dengan alasan sudah tertinggal. Khusus nya di jiwa para anak muda yang cenderng mengikti tren. Membangun perasaan cinta budaya bisa dilakukan dengan menunjukkan suatu identitas dan keistimewaan. Ada banyak budaya dan adat yang ada di Indonesia,salah satunya adat minag kabau.ada dua budaya yang sangat menonjol dalam adat minang, yaitu budaya merantau dan matrilineal. Dua budaya ini sangat mempengaruhi anak-anak minang khususnya di lingkup keluarga dan di lingkup rantauan nya. Rumusan masalahnya adalah bagaimana budaya mempengaruhi karakter anak? Tujuan penelitian ini adalah mengetahui pengaruh budaya dalam mendidik anak di lingkup keluarga. Metode penelitian yang digunakan yaitu metode kualitatif, Pada penelitian ini, saya menggunakan metode penelitian kualitatif deskriptif. Metode ini diterapkan dengan menjabarkan hasil wawancara saya terhadap pasangan suku Minangkabau yang merantau dan menetap dirantauannya.
\end{abstract}

Keywords: Komunikasi lintas budaya, Adat Minangkabau, Matrilineal,Rantau

\section{A. PENDAhuluan}

Komunikasi dan kebudayaan tidak sekedar dua kata tetapi dua konsep yang tidak dapat dipisahkan," harus dicatat bahwa studi komunikasi antarbudaya dapat diartikan sebagai studi yang 
menekankan pada efek kebudayaan terhadap komunikasi ( William B.Hart II, 1996). Salah satu nya adalah budaya matriliniel pada suku Minangkabau.

Masyarakat Minangkabau dikenal sebagai salah satu kelompok etnis di dunia yang menganut sistem kekerabatan matrilineal. Jarang sekali kelompok etnis yang memiliki sistem kekerabatan seperti ini, barangkali hanya dua atau tiga, antara lain, di Afrika Selatan dan India. Penduduk Indonesia yang terdiri dari beragam etnis masyarakat, hampir seluruhnya menganut sistem patrilineal, sementara masyarakat Minangkabau merupakan salah satu yang termasuk etnis terbesar di Indonesia yang memiliki sistem kekerabatan yang berbeda. Karena perbedaan yang unik inilah ia dikenal sampai ke manca negara. Dalam sistem kekerabatan masyarakat Minangkabau yang matrilinal, perempuan mendapatkan posisi yang berbeda jika dibanding dengan perempuan dalam masyarakat patrilineal.

Terdapat delapan ciri sistem matrilineal dalam masyarakat Minangkabau (Muhamad Radjab, 1969:210-211), yaitu:

1. Keturunan dihitung menurut garis ibu;

2. Suku terbentuk menurut garis ibu;

3. Perkawinan exogamy, artinya setiap orang diharuskan kawin dengan orang di luar sukunya;

4. Pembalasan dendam merupakan satu kewajiban bagi seluruh suku;

5. Kekuasaan di dalam suku menurut teori terletak di tangan ibu, meskipun jarang sekali terjadi;

6. Yang sebenarnya berkuasa adalah saudara laki-laki;

7. Perkawinan bersifat matrilokal, yaitu suami mengunjungi rumah isteri;

8. Hak-hak pusaka diwariskan kepada perempuan berdasarkan garis keturunan ibu

Dalam budaya minang juga terdapat budaya merantau bagi anak laki-laki

Dalam kajian antropologis, budaya merantau memberi bekal visi ke depan bagi generasi muda Minang. Budaya merantau mengharuskan anak-anak muda Minangkabau untuk mengasah ilmu dan mencari pengalaman serta berhasil dulu di rantau baru bisa menjadi orang yang berguna bagi diri sendiri, keluarga, dan masyarakat. 
Secara teoritis penelitian ini diharapkan dapat memperkaya penelitian dalam bidang komunikasi terutama komunikasi antarbudaya. Selain itu diharapkan suatu individu dapat mengetahui efek matriliniel dalam komunikasi keluarga.

\section{Tinjauan Pustaka}

Penelitian serupa pernah di lakukan oleh Siti Fatimah (2012) tentang Gender dalam Komunitas Masyarakat Minangkabau; Teori, Praktek dan Ruang Lingkup Kajian yang berkesimpulan bahwa Sistem kekerabatan matrilineal ternyata menempatkan posisi perempuan dan laki-laki secara seimbang. Laki-laki ditempatkan sebagai pelindung dan pengawas, yang dipresentasikan dengan kedudukan terhormat (prestige) sebagai mamak, sedangkan perempuan memiliki akses dalam kepemilikan (property). Sementara dalam pengambilan keputusan seyogianya baik laki-laki maupun perempuan mempunyai akses yang sama. Persoalan terjadi, ketika implementasinya tidak berjalan sebagaimana nilai-nilai budaya tersebut disepakati lagi. Di satu sisi terjadi pelanggaran hak-hak perempuan karena pengaruh budaya patriakhis, dan di sisi lain lakilaki merasa tersubordinasi dengan sistem budaya matrilineal, karena

dikebiri oleh budaya patriakhi. Fakta dan analisis yang telah dikemukakan dalam uraian ini ternyata menunjukkan bahwa terdapat keseimbangan dan kesetaraan antara perempuan dan lakilaki dalam sistem budaya matrilineal, yang mampu membuat masyarakat Minangkabau tersebut bisa survive dan sustainable.

Tidaklah terlalu berlebihan jika penulis berpendapat, kenapa masyarakat Minangkabau ketika masa pergerakan dan awal-awal kemerdekaan sangat banyak melahirkan tokoh-tokoh terkenal di pentas nasional. Sebut saja, Tan Malaka, Moh. Hatta, H. Agussalim, Moh. Yamin, St. Syahrir, Rohana Kudus, Rahmah Elyunusiyah, Hamka, Syafruddin Prawiranegara, Moh. Natsir, dan banyak lagi tokoh-tokoh lainnya. Semua mereka disegani dan sangat diperhitungkan eksistensinya di tengah-tengah komunitas nasional bahkan internasional. Hal demikian, setidak-tidaknya, sangat erat kaitannya dengan sistem matrilineal yang belum banyak mengalami distorsi. Dengan kata lain, masyarakat Minangkabau pada masa itu masih konsisten dalam menjalani adat matrilinealnya. Adat Minangkabau yang disepakati dan dijalankan secara benar dan baik, telah memberikan konstribusi yang cukup signifikan dalam melahirkan tokoh-tokoh atau orang-orang yang berkualitas dari Ranah Minang. Penelitian yang dilakukan oleh Esli Zuraidah Siregar dan Ali 
Amran (2018) berjudul Gender Dan Sistem Kekerabatan Matrilinial. Penelitian ini memaparkan bahwa sistem kekerabatan matrilinial merupakan sistem kekerabatan yang mengambil garis keturunan dan pewarisan harta pusaka melalui garis keturunan ibu. Apabila dikritisi secara seksama, maka sistem kekerabatan yang menganut budaya matrilinial sesungguhnya mengandung nilai keadilan dan kesetaraan gender baik dalam tatanan filosofi maupun sosialnya. Sistem kekerabatan matrilinial menempatkan

posisi perempuan dan laki-laki secara seimbang. Laki-laki mendapat mandat sebagai pengawas dan pelindung yang diberikan kedudukan terhormat sebagai mamak (saudara laki-laki ibu), sedangkan perempuan mendapat akses sebagai kepemilikan. Namun, dalam mengambil keputusan, laki-laki dan perempuan memiliki posisi yang sama.

\section{METODE PENELITIAN}

Pada penelitian ini, saya menggunakan metode penelitian kualitatif deskriptif. Metode ini diterapkan dengan menjabarkan hasil wawancara saya terhadap pasangan suku Minangkabau yang merantau dan menetap dirantauannya, yaitu DKI Jakarta, tepatnya di Kota Administrasi Jakarta Barat. Pasangan itu adalah bapak Martias dan ibu Desty Herawaty. Bapak Martias lahir di Marunggi, 12 Desember 1967, Desty Herawaty lahir di Padang, 6 Desember 1973.

\section{Model Analisis Data}

Metode analisis yang dipakai yaitu teknik analisis data dengan istilah interactive model Miles dan Huberman dalam (Sugiyono, 2012), menjelaskan bahwa kegiatan dalam analisis data kualitatif dilakukan secara interaktif dan berlangsung secara terus menerus sampai selesai. Teknik ini menggunakan tiga komponen yaitu :

Reduksi data adalah meringkas dan memilih hal - hal yang pokok, memfokuskan pada hal - hal yang penting, dengan begitu data yang telah direduksi akan memberikan gambaran yang lebih jelas dan memudahkan peneliti untuk mengumpulkan data.

Penyajian data

Dilakukan dalam bentuk uraian yang singkat, disajikan dalam bentuk bagan, hubungan antar kategori, dijelaskan dengan teks yang bersifat naratif. Penyajian data ini melibatkan dalam pengorganisasian data sehingga seluruh data berkaitan antar satusama lain.

Pengujian kesimpulan 
Dalam hal ini, langkah terakhir dalam pengambilan kesimpulan atau verifikasi. Kesimpulan awal yang bersifat sementara dan dapat berubah bila data tersebut tidak ditemukan bukti - bukti kuat yang mendukung.

\section{HASIL DAN PEMBAHASAN}

Peneliti akan menjelaskan beberapa informan, yaitu identitas bapak Martias terlebih dahulu. Bapak Martias adalah anak dari pasangan bapak Bukia dan ibu Ros, beliau lahir di marunggi. Sejak kecil bapak Martias tinggal bersama "mamak" nya, mamak dalam bahasa Minang berartti paman. Akan tetapi ia lebih sering menghabis kan waktunya di surau, karena dalam budaya Minang anak lakilaki ditak diperbolehkan tidur di rumah dan harus meninap di surau untuk belajar agama serta melatih mental. Bapak Martias memulai rantauannya pada saat menginjak smp, beliau merantau ke Lahat, Sumatera Selatan. Disana ia tinggal bersama paman nya. Selain tinggal ia juga menjadi pengasuh dari anak-anak paman nya yang umur nya tidak jauh oleh nya. Orangtu asuhnya pun sangat keras kepadanya, tidak jarang ia menerima kekerasan fisik.

Karena kondisi yang kurang nyaman, saat menginjak SMA bapak Martias sekolah sekaligus tinggal di SMAN 1 Lahat.

Beliau pindah ke jakarta saat lulus SMA sekaligus tinggal bersama orantuanya untuk pertama kali. Bahkan saat tinggal bersama keluarganya, beliau tidak hanya sendiri. Disana banyak juga anak perantauan yang lain.

Di Jakarta beliau melanjutkan pendidikan di Universitas Pancasila fakultas Hukum.

Hubungan bapak Martias dengan keluarga nya tidak lah harmonis, akibat dari terpisah oleh jarak dalam kurun waktu yang tidak sebentar. Tidak jarang terjadi perkelahian antara beliau dan abak nya.

Selanjut nya penjelasan identitas ibu Desty, ibu desty lahir di padang dan besar di Jakarta. Ia tinggal bersama ibu dan papa nya di daerah Jakarta Timur, tepatnya di Cipinang. Karena lama menetap di Jakarta, kebudayaan Minang yang melekat kurang kuat. Dan bahasa yang di gunakan juga bahasa Indonesia dengan logat betawi. Bu Desty kehilangan ayahnya pada umurnya yang menginjak 15 tahun. Dan meraka bejuang melanjutkan hidup dari warung yang mereka dirikan. Singkat cerita, ibu desty lulus SMA dan melanjutkan kuliah. Bu Desty melanjutkan kuliah di IKIP 
Padang. Disana ia sering kali dimaki karena tidak pandai berbahasa minang, disana ia tinggal dengan Makwo nya, Makwo adalah nenek dalam bahasa minang. Karena perlakuan yang kuran baik yang ia dapat kan saat kuluah di Padang, bu Desty mengalami trauma hingga sekarang. Ia menghindari bercakap menggunakan bahasa minang karena takut di maki atas ketidak pahaman nya.

Singkat cerita Bapak Martias dan Ibu Desty bertemu pada tahun 1999, umur pak martias adalah 33 saat itu, dan bu Desty menginjak 27. Dan singkat cerita mereka menikah pada tahun 2000. Karena adat yang digunakan adlah adat Minangkabau jadi mereka menerapkan budaya "Bajapuik" atau menjemput. Unik nya yang menjemput disini adalah mempelai perempuan dan mempelai laki-laki nyalah yang di jemput, atau dalam kata lain "beli” laki-laki.

Biasanya keluarga Minang menggunakan Bahassa minang dalam berkomunikasi seharihari, akann tetapi keluarga ini tidak menggunakan nya karena trauma yang di alami oleh bu Desty, alhasil anak-anak mereka tidak mahir menggunakan bahasa Minang karena mereka menggunakan Bahasa Indonesia berlogat betawi akibat dari lingkungan Betawi. Karena menghormati trauma bu Desty pak Martias mengalah dan ikut menggunakan bahasa Indonesia dalam berkomunikasi di rumah.

Faktor lingkungan sosial dan dan prilaku berkerja berperan besar dalam kasus ini. Jika dikaji menggunakan teori sebernetika, lingkungan sosial serta prilaku berkerja memberikan timbal balik kepada keluarga ini yaitu bahasa yangdigunakan, serta memudarnya budaya minang dalam keluarga ini.

\section{E. KESIMPULAN}

Budaya bisa memudar akibat beberapa faktor, contoh nya lingkungan sosial, prilaku kerja, histori, dan faktor-faktor lain. Dalam kasus ini budaya memudar akibat dari lingkungan sosial, dan histori.

\section{DAFTAR PUSTAKA}

Littlejohn, S. W., \& Foss, K. A. (2009). Teori Komunikasi. Jakarta: Salemba Humanika 
Budyatna, M. (2011). Teori Komunikasi Antarpribadi. Kencana Prenada Media Group. Astuti, M. T. (2017). Persepsi Budaya Pemandu Wisata Terhadap Wisatawan Korea Selatan (Studi Deskriptif Kualitatif Persepsi Budaya Pemandu Wisata Terhadap Wisatawan Korea Selatan Di Jogjakarta) (Doctoral Dissertation, Universitas Mercu Buana Yogyakarta). Fatimah, S. (2012). Gender Dalam Komunitas Masyarakat Minangkabau; Teori, Praktek Dan Ruang Lingkup Kajian. Kafaah: Journal Of Gender Studies, 2(1), 11-24.

Https://Www.Gurupendidikan.Co.Id/Metode-Penelitian-Kualitatif/. (2019, November). Metode Penelitian Kualitatatif Menilik Budaya 'Beli' Laki-Laki Di Tradisi Perkawinan Ranah Minang. (N.D.). Retrieved From Https://Www.Covesia.Com/Archipelago/Baca/71904/Menilik-Budaya-Beli-Laki-Laki-DiTradisi-Perkawinan-Ranah-Minang

Siregar, E. Z., \& Amran, A. (2018). Gender Dan Sistem Kekerabatan Matrilinial. Jurnal Kajian Gender Dan Anak, 2(2), 133-146.. 